\title{
A PESSOA E O IMPESSOAL: \\ UMA CONFRONTAÇÃO ENTRE O PENSAMENTO \\ FENOMENOLÓGICO DE MAX SCHELER E \\ DE MARTIN HEIDEGGER
}

Alexandre Franco de Sá

Universidade de Coimbra

Partindo ambos da herança da fenomenologia de Edmund Husserl, Max Scheler e Martin Heidegger partilham um destino comum que, ao mesmo tempo e de um modo paradoxal, os separa radicalmente. Por um lado, eles herdam a crítica ao psicologismo e à herança neokantiana da filosofia transcendental, tentando completar, cada um a seu modo, a superação fenomenológica do sujeito enquanto entidade marcada por uma identidade substancial situada, de algum modo, num plano anterior e subjacente ao mundo. Assim, tanto no pensamento de Scheler como no de Heidegger, o ponto de partida encontra-se na tentativa de pensar o homem e o seu modo de ser a partir de um paradigma que escape à determinação do legado aristotélico de uma ontologia substancialista. Por outro lado, Scheler e Heidegger afastam-se precisamente quando desenvolvem o seu pensamento a partir do seu ponto de partida comum. Como se sabe, a partir de 1913 e através de uma confrontação com a ética kantiana presente em O Formalismo na Ética e a Ética Material dos Valores, Scheler desenvolverá uma ética de cariz personalista e procurará encontrar no conceito de pessoa o resultado último do seu afastamento em relação à noção tradicional de um sujeito concebido como uma identidade substancial. Heidegger, por sua vez, a partir da publicação da primeira parte de Ser e Tempo em 1927, esboçará o projeto de uma ontologia fundamental, cujo acesso fenomenológico consistiria numa analítica do modo de ser do ente que - conforme a sua expressão - nós mesmos somos a cada passo, deslocandō

\section{Phainomenon, n. ${ }^{\circ} 24$, Lisboa, pp. 79-89}

DOI: 10.2478 /phainomenon-2012-0006

(C) 2012 de Sá. This is an open access article licensed under the Creative Commons AttributionNonCommercial-NoDerivs License (http://creativecommons.org/licenses/by-nc-nd/3.0/). 
a questão da ética para um momento posterior da elaboração do projeto (aliás nunca levado a cabo) e recusando a referência antropológica à pessoa e à vida fáctica para se centrar na análise ontológica do "ser-aí", o Da-sein.

Face à semelhança do ponto de partida e ao afastamento do ponto de chegada do percurso filosófico de Scheler e Heidegger, o percurso que nos propomos levar a cabo pretende estabelecer uma relação entre os dois mostrando de que modo na sua oposição se manifesta não um puro e simples afastamento, mas um diálogo implícito. Para tal, torna-se necessária a adopção na apresentação de uma estrutura circular, fazendo ver como, por um lado, no ponto de partida de Heidegger se encontra uma problematização consistente do humanismo personalista subjacente à posição de Scheler e como, por outro lado, no personalismo de Scheler se encontra uma resistência potencial aos perigos que se escondem na abordagem do ente «que de cada vez nós mesmos somos» ${ }^{1}$ pelo ponto de vista da ontologia fundamental de Heidegger. Assim, num primeiro momento do nosso percurso, procuraremos mostrar em que medida o projeto ético de Scheler, apesar de abrir o conceito de pessoa como "atualidade continuada» ${ }^{2}$ e, nessa medida, como um ente irredutível à noção tradicional de substância, ainda participa, ao caracterizá-lo como um ente vivente e corpóreo dotado de valor, do modo de ser que está na base desta mesma noção: o modo de ser daquilo a que Heidegger chamou precisamente o Vorhandensein, o estar presente enquanto subsistente, isto é, enquanto vida subjacente a um conjunto de experiências vividas ou vivências. Procuraremos mostrar como o percurso de Heidegger pode ser compreendido justamente como uma tentativa de pensar para além do quadro desta compreensão do ser, pondo em causa quer o humanismo antropocêntrico implícito na análise de Scheler quer a própria possibilidade de elaboração de uma ética derivada deste humanismo. Num segundo momento, procuraremos mostrar como o projeto de Heidegger da constituição de uma ontologia fundamental, com o carácter problemático que nele adquire a possibilidade de elaboração de uma ética, não pode deixar de cair em perigos para os quais a abordagem de Scheler poderia constituir uma resposta adequada.

O ponto de partida da análise de Scheler torna-se inteiramente claro se o situarmos na sua contraposição à filosofia transcendental kantiana, a partir de cujo formalismo ético a sua posição emerge como a elaboração de uma ética material dos valores. Na Crítica da Razão Pura, Kant tinha estabelecido os fundamentos para uma crítica da metafísica tradicional em geral, com a sua

Martin Heidegger. Sein und Zeit. Tübingen: Max Niemeyer, 1986, p. 41.

2 Max Scheler. Der Formalismus in der Ethik und die materielle Wertethik. Bern: Francke Verlag, 1954, p. 105 (nota 1). 
anfibolia e a sua tomada de fenómenos como númenos, e para uma crítica da concepção tradicional do sujeito, em particular. Se esta concepção se baseara na representação cartesiana do sujeito moderno como res cogitans, se esta concepção tinha na sua base a compreensão do sujeito como uma identidade substancial subjacente ao ato de pensar, Kant problematiza esta compreensão, referindo-se a este sujeito como um simples "eu penso" cuja unidade acompanha e unifica numa síntese a multiplicidade de todos os seus objetos. Uma tal problematização torna-se clara nas considerações de Kant em torno da "apercepção transcendental", isto é, em torno da autoconsciência pela qual um $e u$ enquanto sujeito pensante se intui a si mesmo enquanto objeto pensado. Kant separa o eu enquanto sujeito pensante do eu enquanto objeto pensado, e pergunta: «Como poderá o eu, o eu penso, distinguir-se do eu que se intui a si próprio $[. .$.$] e todavia ser idêntico a este último, como o mesmo sujeito? Como,$ portanto, poderei dizer que eu, enquanto inteligência e sujeito pensante, me conheço a mim próprio como objeto pensado, na medida em que me sou, além disso, dado na intuição, apenas à semelhança de outros fenómenos, não como sou perante o entendimento, mas tal como me apareço?» ${ }^{3}$. A resposta de Kant é clara no sentido de dizer que o sujeito, longe de ser uma unidade substancial, não é senão uma representação que «deve poder acompanhar» ${ }^{4}$ todas as representações possíveis; e em afirmar que, tratando-se o eu de uma representação, conhecemos o sujeito «apenas como fenómeno e não tal como é em si» ${ }^{5}$ : «não tenho conhecimento de mim tal como sou, mas apenas tal como apareço a mim mesmo» ${ }^{6}$.

Para Scheler, esta deslocação kantiana do sujeito de uma identidade substancial originária para uma representação ou um mero "fenómeno" não seria, contudo, suficiente para compreender o ser desse mesmo sujeito. Um tal sujeito seria essencialmente, na medida em que se realizaria através da multiplicidade das suas vivências, um estar em ato. E, na medida em que o seu modo de ser consistiria nesta atualidade, um tal sujeito não poderia ser propriamente um sujeito, isto é, o eu de uma simples relação sujeito-objeto que deveria ser, na sua consciência de si, percepcionado enquanto objeto. Como escreve Scheler: «Também o "eu" [...] é ele mesmo ainda um objeto. Mas nunca um ato é também um objeto; pois pertence à essência do ser dos atos serem vivenciados apenas na própria execução e apenas serem dados na

${ }^{3}$ Immanuel Kant. Crítica da Razão Pura. Trad. Alexandre Fradique Morujão e Manuela Pinto dos Santos. Lisboa: Gulbenkian, 1989, p. 156 [KrV. B 155]:

${ }^{4}$ Op. cit., p. 131 [KrV. B 132].

Op. cit., p. $157 \mathrm{KrV}$. B 157.

6 Op. cit., p. $158 \mathrm{KrV}$. B 157. 
reflexão. Assim, um ato nunca pode voltar a ser objeto através de um segundo ato, que como que olhe para trás. Pois também na reflexão, que torna o ato ainda passível de ser sabido para além da sua execução (ingénua), ele nunca é "objeto"; o saber reflectido "acompanha-o", mas não o objetiva»". Assim, se o sujeito kantiano não era uma substância idêntica a si mesma, mas um eu auto-consciente que, como tal, se daria como objeto para ele mesmo, o sujeito de Scheler não é propriamente um eu, mas um conjunto de atos que, enquanto tal, é já a partir da sua relação livre com o seu mundo.

Se há entes vivos que são determinados pelo mundo enquanto ambiente que os envolve (Umwelt), o sujeito scheleriano, na medida em que é agente, é essencialmente livre nessa relação. É a essa liberdade capaz de agir que Scheler chama "espírito", Geist. «Um ser "espiritual”» - escreve Scheler em A Situação do Homem no Cosmos - «já não está vinculado aos impulsos e ao ambiente, mas é "livre do ambiente" e, como o queiramos chamar, "aberto ao mundo": um tal ser tem "mundo" $»^{8}$. E a este "ser espiritual" constituído pelos seus atos livres chama Scheler pessoa: «A pessoa nunca pode ser pensada como uma coisa ou uma substância que tivesse quaisquer faculdades ou forças, entre as quais também uma "faculdade" ou uma força" da razão, etc.. Pessoa é antes a imediata unidade co-vivenciada do vivenciar - não uma coisa apenas pensada atrás e fora do que é imediatamente vivenciado»?. Assim, se a pessoa se caracteriza como a unidade das suas vivências, e não como uma "coisa" substancial que está atrás ou por baixo delas como seu fundamento, Scheler pode dizer, pela negativa, que a pessoa é o ente que é insusceptível de ser tratado como objeto. Daí que Scheler escreva: «O espírito é o único ser que é ele mesmo incapaz de ser objeto - ele é pura atualidade, tem o seu ser apenas na livre execução dos seus atos. O centro do espírito, a "pessoa", não é um ser nem objetual nem coisal, mas apenas uma constante articulação ordenada de atos (essencialmente determinada) que se realiza a ela mesma. O que é anímico não se realiza a "si mesmo": é uma série de acontecimentos "no" tempo que, a partir do centro do nosso espírito, ainda, em princípio, conseguimos contemplar, que podemos ainda tornar objetual na percepção e observação internas. Tudo o que é anímico é passível de ser objeto - mas não $\mathrm{o}$ ato do espírito, a intentio, aquilo que vê ainda os próprios acontecimentos anímicos. Ao ser da nossa pessoa só nos podemos juntar, concentrarmo-nos

${ }^{7}$ Max Scheler. Op. cit., p. 385.

${ }^{8}$ Max Scheler. Die Stellung des Menschen im Kosmos. ed. Manfred Frings. Bonn: Bouvier Verlag, 1995, p.38.

${ }^{9}$ Max Scheler. Der Formalismus in der Ethik, p. 382. 
para ele-mas não objetivá-lo» ${ }^{10}$.

A caracterização da pessoa enquanto espírito, enquanto pura atualidade, conduz Scheler à tentativa de pensar o ser do homem e a sua ação no mundo de um modo distinto da sua abordagem tradicional. Por outras palavras, esta caracterização conduz Scheler à tentativa de desenvolver uma antropologia filosófica e uma ética que lhe fosse correspondente. Se o homem é, enquanto pessoa, já sempre intentio, a sua relação com o mundo não é redutível a uma consideração neutra de objetos; longe de ser redutível àquilo que se poderia caracterizar como a relação de representação entre sujeito e objeto, a relação do homem com o mundo é sempre já afetada por um sentir, por um Fühlen que o coloca fora da neutralidade. Por outras palavras, ao ser pessoa, o homem é já sempre marcado por uma valoração afetiva na sua relação com o mundo, e é aos objetos do sentir que Scheler chama "valores". Os valores são assim, para Scheler, objetos de uma intuição que se orienta para eles, e é enquanto objetos intencionais que eles têm a possibilidade de fundar uma ética. Uma tal ética é, por um lado, independente da experiência empírica dos bens e, nesse sentido, inteiramente a priori. Os bens são portadores de valores e os valores são qualidades de valor, mas não se confundem com os bens nem lhes são redutíveis enquanto objetos. Pelo contrário, os valores são os objetos próprios de uma intuição emocional específica, a qual é originária e, nessa medida, de modo nenhum depende do contacto com os bens. Como escreve Scheler: «Há qualidades de valor genuinas e verdadeiras que apresentam um âmbito próprio de objetos, que têm as suas relações e conexões particulares e que, enquanto qualidades de valor, podem ser maiores e mais pequenas, etc. Mas se esse é o caso, então pode vigorar entre elas também uma ordem e uma hierarquia que é totalmente independente da existência de um mundo de bens no qual se vem a manifestar, e também do movimento e da mudança deste mundo de bens na história e que, para a sua experiência, é "a priori"»" Por outro lado, se a possibilidade de estabelecer uma hierarquia de valores independentemente dos bens possibilitaria uma ética a priori, a objetividade dos valores, a circunstância de os valores não derivarem da forma do sujeito que os estabelece, mas de uma matéria que se oferece à intentio emocional desse mesmo sujeito, atribui a esta ética $a$ priori um carácter material que não põe em causa, como pensaria Kant, o seu apriorismo. Como conclui Scheler: «Todos os valores (também os valores "bom" e "mau") são qualidades materiais que têm entre si uma ordem determinada segundo o superior e o

\footnotetext{
${ }^{10}$ Max Scheler. Die Stellung des Menschen im Kosmos, p. 48.

"Max Scheler. Der Formalismus in der Ethik, pp. 37-38.
} 
inferior ${ }^{12}$. A ética scheleriana realiza-se, então, explicitamente como uma tentativa de ultrapassagem do formalismo a que a filosofia transcendental kantiana parecia ter condenado a ética. Se Kant tinha procurado no imperativo categórico da razão pura prática a fonte para a determinação da ação moral, na medida em que esta se determinaria por um móbil decorrente da forma desse imperativo, Scheler estabelece a experiência do valor na sua doação à intentio emocional, presente na pessoa enquanto atualidade e relação originária com o mundo, como a base para a elaboração de uma ética material a priori.

A partir da materialidade a priori dos valores, Scheler desenvolve diferentes modalidades valorativas - o valor do agradável, os valores vitais, os valores espirituais, os valores do sagrado -, refletindo também sobre os critérios para a sua diferenciação e hierarquização. E é a partir da reflexão sobre estes critérios que Scheler terá ocasião, também, de introduzir uma referência fundamental àquilo a que chama "valores absolutos". Na medida em que são correlatos de atos intencionais, os valores são sempre relativos a esses mesmos atos. No entanto, se um valor for relativo a um sentir puro, enquanto puro ato intencional, um tal valor oferece-se como um valor absoluto. É o caso, para Scheler, dos valores éticos. Assim, se algo agradável só pode ser sentido como tal por um sujeito senciente e é, nesse sentido, relativo a este mesmo sujeito, do mesmo modo que o valor vital da saúde, da nobreza ou da potenciação da vida só pode ser sentido por um ser vivo, um valor ético é absoluto na medida em que se constitui como correlato intencional da intentio de um sentir puro. Se um valor relativo é valor apenas para o ato de sentir que o determina, e se o é, portanto, em função da determinação deste mesmo ato, o valor absoluto é válido a priori em função da sua materialidade, em função da sua pura doação a um puro ato de sentir, a uma pura percepção afetiva, e não em função da forma deste mesmo ato. Como escreve Scheler: «O valor do agradável é "relativo" ao ser "que sente sensivelmente"; também a série de valores "nobre e comum", por exemplo, é relativa ao "ser vivo". Pelo contrário, os valores absolutos são aqueles valores que existem para um sentir "puro" (preferir, amar), isto é, para um sentir independente da essência da sensibilidade e da essência da vida, no seu modo e nas suas leis de funcionar. Deste tipo são, por exemplo, os valores éticos. No sentir puro conseguimos - sem realizar as funções do sentimento sensível através das quais fruímos nós mesmos (ou outros) o que é agradável - "compreender" (e conforme ao sentimento) o sentir destes valores; mas não os conseguimos nós mesmos sentir. Assim Deus pode “compreender" as dores sem as sentir» ${ }^{13}$.

2 Op. cit., p. 40.

13 Op. cit., p. 118. 
Dir-se-ia, então, que Scheler estabelece entre os conceitos de valor absoluto e de pessoa, enquanto protagonista do ato de um "sentir puro", uma circularidade em que importa reparar. Por um lado, o valor absoluto remete para o ato de sentir puro, constitutivo da pessoa, não na medida em que é por ela determinado, mas na medida em que a pessoa é o âmbito no qual o valor absoluto se manifesta. Por outro lado, a pessoa remete para o valor absoluto na medida em que, enquanto instância na qual o valor absoluto se dá, é ela mesma portadora deste valor. Como escreve Scheler: «Os valores éticos, em geral, são valores cujos portadores nunca podem ser dados (originariamente) como "objetos", pois estão essencialmente do lado da pessoa (e do ato). Pois nunca a pessoa nos pode ser dada como "objeto", nem nenhum ato. Na medida em que, de uma maneira qualquer, "objetivarmos" um homem, o portador dos valores éticos fica necessariamente fora de vista» ${ }^{14}$. Na sua ética formalista, Kant falara do dever moral como ratio cognoscendi da liberdade de um sujeito racional, a qual seria conhecida a partir do dever na medida em que a própria liberdade seria a sua ratio essendi, ou seja, na medida em que a forma da razão seria a determinação do próprio dever. Na sua ética material, pelo contrário, dir-se-ia que Scheler fala de uma pessoa cujo "sentir puro" é a ratio cognoscendi do valor absoluto, o qual é a própria ratio essendi da pessoa enquanto portadora desse mesmo valor.

É em contraposição a esta atribuição à pessoa de um valor absoluto, e particularmente em contraposição ao humanismo que está subjacente a esta mesma atribuição, que o pensamento de Heidegger se vai, antes de mais, situar. Para Heidegger, dir-se-ia que a atribuição à pessoa de um valor absoluto consistiria num recuo face à perspectiva que, através da crítica ao sujeito kantiano, Scheler tinha introduzido acerca do ser do homem. Se Scheler tinha atribuído a este ser uma pura atualidade, uma tal atribuição seria incompatível com a representação da essência do homem como pessoa, isto é, como uma base substancial portadora de um valor. Apresentar o homem, na sua essência, como uma pessoa e, nesta medida, como portador de um valor absoluto corresponderia a representar um tal ente como uma substância presente no mundo, como uma "coisa" na qual a qualidade de valor estaria depositada. Ora, as análises de Scheler, que Heidegger acolhe, teriam mostrado precisamente que o ente que o homem é seria, na sua essência, uma relação, um ser-no-mundo cujo âmago se encontra precisamente não em ser uma "coisa" que está dentro do mundo, mas em ser uma relação originária com o mundo, um estar a passar por ele e estar, nesse sentido, "junto dele" (Heidegger chama-lhe um "ser-em" [In-sein] que não é, nesse sentido, um

${ }_{14}$ Op. cit., p. 106. 
"estar dentro de..." mas um "ser junto a" $[$ Sein bei $])^{15}$. Assim, para Heidegger, tratando-se de analisar um ente cuja constituição ontológica seria determinada por este estar "junto ao" mundo, a análise a levar a cabo deveria partir não de uma ética assente na pressuposição de um valor absoluto da pessoa, mas de um acesso fenomenológico ao modo como quotidianamente o homem está a ser. Assim, se Scheler procurava fundamentar o homem como pessoa e valor absoluto, Heidegger procurará abordar o ser do homem não a partir de uma perspectiva ética ou antropológica, mas a partir de uma ontologia que fosse aberta pelo acesso fenomenológico ao modo de ser do homem enquanto ser-no-mundo. Por outras palavras, se Scheler partia do homem como pessoa, e da pessoa como ente dotado de um valor absoluto, Heidegger abordará o ser do homem a partir não do que ele é, o que implicaria tomá-lo já como algo substancial, mas do modo como ele é (ou está a ser) primeiro e quase sempre (zunächst und zumeist).

Para assinalar esta diferente abordagem, Heidegger caracteriza o homem como um ente cujo ser consiste precisamente em ser-no-mundo no sentido em que é apropriado pelas estruturas constitutivas desse mesmo ser. A designação desse ente como "ser-aí" (Da-sein) assinala precisamente essa apropriação, e esta apropriação traduz-se numa tendência deste ente para, no modo como é primeiro e quase sempre, dispersar-se na sua relação quotidiana com as coisas com que lida no mundo. Ao sujeito desta quotidianeidade dispersa chama Heidegger, como se sabe, das Man, "a gente". E é para a caracterização do modus quotidiano de ser no mundo que Heidegger recorre ao conceito de inautenticidade ou impropriedade (Uneigentlichkeit): «A gente é no modo da não-autonomia e da inautenticidade ${ }^{16}$. Isso significa que, para Heidegger, na medida em que se encontra já sempre facticamente disperso no mundo com que lida, o ente humano não é primeiro e quase sempre ele mesmo, mas antes "a gente", um ente impessoal e indiferenciado dos outros. À pergunta acerca de "quem" é o Dasein, responde Heidegger: «O quem não é este nem aquele, não se é, nem é alguns nem a soma de todos. $\mathrm{O}$ "quem" é o neutro, a gente»" Tal quer dizer que o Dasein não é um si-mesmo situado aquém da sua "vida quotidiana", e depositário de uma dignidade ou de um valor absoluto, mas que o seu si-mesmo se confunde primeiro e quase sempre com a própria gente: «O si-mesmo do Dasein quotidiano é a própria gente, que distinguimos do si-mesmo autêntico, isto é, do si mesmo que se capta propriamente. Enquanto a própria gente, o respectivo Dasein está disperso pela gente e tem primeiro

15 Cf. Martin Heidegger. Sein und Zeit, p. 53 ss.

16 Op. cit., p. 128.

17 Op. cit., p. 126. 
de se encontrar. [...] Primeiro não "sou eu" no sentido do si-mesmo próprio, mas os outros no modo da gente. É a partir dela e enquanto ela que sou "dado" primeiro a mim "mesmo". Primeiro, o Dasein é a gente e quase sempre permanece assim» ${ }^{18}$. Longe de afirmar que o Dasein é uma pessoa dotada de um valor intrínseco, e que pode também dispersar-se ou alienar-se no mundo em que se encontra lançado, Heidegger aborda a constituição ontológica deste ente a partir de uma dispersão (Zerstreuung) e de uma alienação originárias, recusando implicitamente a possibilidade de lhe ser reconhecido um valor absoluto originário. E tal recusa tem duas consequências fundamentais que importa assinalar.

Por um lado, se o homem, na sua constituição ontológica, não pode ser considerado como uma pessoa portadora de um valor absoluto, se ele é primeiro e quase sempre a gente na sua indiferenciação em relação aos outros, tal quer dizer que a análise de Heidegger corresponde a uma rejeição do humanismo, no sentido de uma desvalorização do homem. Heidegger assume esta rejeição do humanismo explicitamente, afirmando que o homem não pode ser um "valor supremo" na medida em que ele é, na sua constituição ontológica, caracterizado por uma pertença e por uma apropriação. Esta desvalorização do homem estende-se desde a contestação de Heidegger ao "liberalismo" que coloca o homem como "valor supremo", seja sob a forma do indivíduo seja sob a forma do povo (daí a sua recusa do pensamento "völkisch" do nacional-socialismo, na década de 1930), até àquilo a que pensadores como Leo Strauss chamaram o "historicismo" de Heidegger, ou seja, à sua compreensão do homem como o simples "aí" em que acontece (geschieht) e se desdobra uma "história do ser" que dele se apropria e constitui a sua essência. Em Ser e Tempo, ser si-mesmo é, para o Dasein, decidir-se a assumir a situação fáctica como aquilo a que se poderia chamar uma potência apropriadora (à qual Heidegger chamará, depois de 1936, o Ereignis). A resolução (Entschlossenheit) com que Heidegger caracteriza a autenticidade do Dasein traduz-se precisamente numa decisão fáctica de assumir uma tal pertença: «A assunção resoluta do "aí" fáctico próprio significa, ao mesmo tempo, a decisão para a situação» ${ }^{19}$. Uma tal pertença assinala ao homem um "destino" no seio da sua geração, do seu povo e da sua história ${ }^{20}$. A partir da década de 1930, Heidegger intensificará ainda esta pertença do homem a um "destino", assinalando que a decisão reside, em última análise, não no homem, mas na de-cisão do próprio ser, enquanto história do ser e acontecimento apropriador do homem (Ereignis). Por mais

\footnotetext{
18 Op. cit., p. 129.

19 Op. cit., p. 382.

${ }^{20}$ Op. cit., pp. 384-385.
} 
que o homem se possa conceber como um ente livre, cujo existir autêntico ou inautêntico o confronta com o apelo para uma decisão, como Heidegger o apresenta em Ser e Tempo, o homem já não tem para Heidegger o valor de um decisor, mas ele é antes apenas o "aí" no qual a de-cisão do ser, na sua história, acontece. Como escreve Heidegger em meados da década de 1930, nos textos que darão posteriormente importantes volumes póstumos como Contribuições para a Filosofia e Meditação: «A decisão pertence à essência do próprio Ser e não é nada que seja feito pelo homem, pois este mesmo recebe a partir desta de-cisão e da sua recusa o carácter de fundamento e de fundador ou o carácter ocupado ou fugidio da sua essência. O Ser de-cide» ${ }^{21}$.

Por outro lado, a desvalorização do homem pela ontologia fundamental tem também como consequência inevitável uma desvalorização da própria ética. Para Heidegger, a analítica do ser-no-mundo, partindo da análise fenomenológica da sua quotidianeidade, constituiria uma ontologia fundamental, a partir da qual se poderia elaborar, apenas num segundo momento, aquilo a que Heidegger chamou metaontologias. No seio destas teria lugar uma metaontologia do ser-no-mundo, uma ontologia regional do ser do Dasein, na qual, escreve Heidegger, exclusivamente poderia ser tratada «a questão da ética $\aleph^{22}$. Por outras palavras, a ontologia fundamental de Heidegger não apenas põe em causa o conteúdo de uma ética personalista, mas afecta também o estatuto originário da própria ética no âmbito da abordagem filosófica do modo de ser do homem.

Tendo em conta esta dupla consequência daquilo a que se poderia chamar a recusa por Heidegger do personalismo de Scheler, tendo em conta quer a rejeição do humanismo quer a desvalorização da ética, torna-se claro o perigo que a proposta da ontologia fundamental encerra. Diante de uma tradição humanista antropocêntrica, que coloca o homem como "valor supremo" e todos os restantes entes ao seu serviço, a proposta ontológica de Heidegger tem certamente o mérito de salientar não apenas a fragilidade e a finitude que marcam o ser do homem, mas os perigos que se encerram na desmesura, na hybris trágica, contidos na tentativa de responder à fragilidade e à finitude humanas com uma atitude imperial e - dir-se-ia hoje - "especista" diante do ente no seu todo. A meditação de Heidegger em torno da técnica enquanto consumação dessa atitude, a qual aparece como já decidida pelo primeiro início (metafísico) da história do ser como o seu destino, procura

${ }^{21}$ Martin Heidegger, Besinnung, ed. Friedrich-Wilhelm von Herrmann. Frankfurt: Vittorio Klostermann, 1997; Gesamtausgabe vol. 66, p. 46.

${ }^{22}$ Cf. Martin Heidegger. Metaphysische Anfangsgründe der Logik im Ausgang von Leibrïz. Frankfurt: Vittorio Klostermann, 1978; Gesamtausgabe. vol. 26, p. 199. 
sobretudo apontar para tais perigos, bem como evocar um "outro início" que pudesse emergir como uma salvação. No entanto, sob a referência de Scheler, importaria ter presente também os perigos que se escondem num pensar que explicitamente subtrai ao homem um valor absoluto e que desvalorize a ética (ou que, pelo menos, se contraponha a uma ética humanista, que encontre no homem um valor único). Na maior parte das questões que marcam a nossa contemporaneidade filosófica, talvez o problema central seja justamente o de saber como é possível que a deposição do antropocentrismo próprio de uma metafísica substancialista tradicional, e das suas consequências no plano da relação entre o homem e o seu mundo, não tenha por consequência a simples entrega do homem a potências que o apropriam, mobilizam, manipulam e subordinam. Scheler teria uma palavra a dizer a Heidegger quando este, no final da sua Questão da Técnica, apontou para a necessidade de com o perigo crescer também a salvação.

\section{RESUMO}

A presente comunicação parte da semelhança entre Max Scheler e Martin Heidegger na sua abordagem do modo de ser do homem como um modo de ser não substancial. Quer a "Pessoa" de Scheler quer o "Dasein" de Heidegger aparecem como atos, determinados pelo seu estar já a ser no mundo, e não como entidades substanciais possuidoras de uma identidade colocada num plano anterior à sua "atualidade". No entanto, Scheler e Heidegger extraem deste pensamento inicial comum um percurso divergente: o primeiro dirigido à pessoa e o segundo indo ao encontro do "impessoal" (das Man). A comunicação pretende mostrar precisamente o caminho desta divergência.

Palavras-chave: Heidegger - Scheler - Pessoa - Impessoal

\section{ABSTRACT}

The Person and the Inpersonal: confronting Max Scheler's phenomenological thought with Heidegger's. This essay starts from a similarity between the thought of Max Scheler and Martin Heidegger in their correspondent approaches to the way the being of the human as non-substantial. Both Scheler's notion of "Person" and Heidegger's notion of "Dasein" are conceived of as acts, always already determined by their being-in-the-world, and not as substantial entities with a kind of identity previous to their "actuality". Nonetheless, Scheler and Heidegger extract from that originally common thought divergent pathways of thinking: whereas the first one addresses the mode of being of the Person, the second derives to the "impersonal" (das Man). This text aims at showing precisely the way of that divergence.

Keywords: Heidegger - Scheler - Person - Inpersonal 